3 Research Square
Preprints are preliminary reports that have not undergone peer review.

They should not be considered conclusive, used to inform clinical practice, or referenced by the media as validated information.

\title{
Yeast library creation using the SWAT method
}

\author{
Maya Schuldiner ( $\nabla$ maya.schuldiner@weizmann.ac.il ) \\ Weizmann Institute of Science \\ Ido Yofe \\ Weizmann Institute of Science \\ Uri Weill \\ Weizmann Institute of Science
}

\section{Method Article}

Keywords: Saccharomyces cerevisiae, genetics, yeast collection, systems biology

Posted Date: June 19th, 2018

DOI: https://doi.org/10.1038/protex.2018.037

License: (c) (i) This work is licensed under a Creative Commons Attribution 4.0 International License.

Read Full License 


\section{Abstract}

Collections of modified strains of the yeast Saccharomyces cerevisiae revolutionized the systematic study of cell biology. To extensively increase the number of such libraries and the types of information that can be gleaned from them, we have recently devised an approach, termed SWAp-Tag \(SWAT). SWAT relies on a parental library to rapidly, easily and efficiently create additional collections. In this protocol we describe how to use the genome wide SWAT parental library to generate any tagged library of choice.

\section{Introduction}

The SWAp-Tag \(SWAT) method removes the major hurdles of yeast strain collection \(library) building cost, time and labor, making creativity the only barrier to designing and building new libraries. The methodology is based on a template \(_acceptor_) library, SWAT-GFP, which can be "swapped" into any other library of choice. Using the "template library" of strains, in which an acceptor module with a GFP was integrated into a different gene in each strain $\backslash$ (at the $N^{\prime}$ terminus), one can easily create any other yeast collection with their desired genomic modification or tag inserted into each ORF at the $\mathrm{N}^{\prime}$. The method relies on the Synthetic Genetic Array $\backslash(\mathrm{SGA})$ procedures to cross the SWAT library with a _donor_ strain. The donor strain harbors the desired module to be inserted on a donor plasmid, and an inducible IScel restriction enzyme that facilitates high efficiency of swapping. The SWAT methodology is easy and fast, highly efficient and accurate. It enables any lab to create their own "tailor made" strain collection in a matter of a few weeks.

\section{Reagents}

To create a new yeast library one must have in hand the three basic features of the method: See figure in Figures section. All template plasmids, strains and libraries can be obtained from the Schuldiner lab \ (maya.schuldiner at weizmann.ac.il) A comprehensive list of common media, reagents and plastic-ware required for yeast libraries manipulation is elaborated by Cohen et. al. \(Cohen and Schuldiner, 2011). Custom DNA oligos need to be synthesized for cloning of the donor plasmids, as well as validation of the cloning, and later on for successful library tag swapping. Common oligos are: L1 CHK F cgtacgctgcaggtcgac L1 CHK R catcgatgaattctctgtcg sfGFP CHK R ttcgaatttcacttctgctc NOP1 pr CHK F agccaacaagttttccttac

\section{Equipment}

Routine yeast growth equipment such as a $30^{\circ} \mathrm{C}$ incubator and tube shaker for plates and culture growth is required. For a laboratory that routinely maintains and manipulates a large number of libraries, a Singer RoTor system is recommended $\backslash$ (Singer Instruments).

\section{Procedure}


**Summary** First, the desired genomic modification must be cloned into a donor plasmid. This plasmid should then be transformed into a SWAT donor strain, which already contains the SGA procedure genetic traits, and is compatible with the SWAT method as it harbors a galactose induced I-Scel. Once introduced with the donor plasmid the donor strain is crossed with the SWAT library, and the following steps of the SGA process are performed: mating, diploid selection, sporulation, haploid selection and double-mutant selection. At this point, swapping of the desired module into the genome is induced by replicating the double mutant plates onto galactose containing media. Finally, selection for positively swapped yeast is performed by 5-FOA \(negative selection for the SWAT acceptor module), and/or by a selection marker introduced with the donor module. plasmid is a yeast shuttle vector and must contain the following features: $\backslash$ (Note: All of the below instructions are for $\mathrm{N}^{\prime}$-tag swapping with the available SWAT-GFP library) A. Bacterial origin of replication and selection marker, for maintenance and plasmid production. B. Yeast centromere and autonomously replicating sequence $\backslash(\mathrm{CEN}-\mathrm{ARS})$. - This feature ensures a low-copy number of the plasmid per cell, helping avoid a possible problem of non-cut plasmid after Scel induction, and recombination between copies of donor plasmids. C. Yeast selection marker. Possible common markers that can be used are: KAN, NAT, MET, and Bleomycin. \(Hygromycin may be used if not used as the swap selection). Markers that cannot be used, as they are utilized as SGA markers are: URA \(the SWAT library marker), HIS, LEU, LYS, and ARG, as well as the CAN1 and LYP1 transporters. D. Two Scel sites, directly up- and downstream of the swap module. The I-Scel site sequence is $\backslash$ (restriction site alone underlined) : $5^{\prime}$ agttacgctagggataacagggtaatatag 3'. E. Two recombination sequences, homologous to regions in the SWAT module flanking the SWAT module Scel site. These can be any combination of the following: See figure in Figures section. F. Optional - selection marker. See figure in Figures section. G. The desired genomic modification. This may be either a promoter, a promoter and a tag, or any other regulatory element $\backslash$ (protein coding or other). • One can also introduce a tag at the $5^{\prime}$ end, to be driven by each gene's native promoter, and another promoter + tag at the $3^{\prime}$ end, to be fused to each protein. P Proteins containing regulatory features at their $5^{\prime}$ end were tagged downstream to these features with a SWAT module which has a generic feature in exchange $\backslash$ (such as signal peptides). Therefore, non-seamless swapping donor plasmids should contain another version of these features as well $\backslash$ (such as a different signal peptide), and introduced separately to assemble a donor strain to be crossed with this subset of strains of the SWAT library. To ease the cloning of donor plasmids, several template plasmids were prepared by us and are freely available. These plasmids contain all the features above, and should only be modified by insertion of the desired genomic modification to be introduced instead of the SWAT tag in the library. The plasmids do not contain multiple cloning sites and therefore we highly recommend using either restriction free $\backslash$ (RF) cloning $\backslash$ (Unger et al., 2010) or Gibson assembly $\backslash$ (Gibson et al., 2009) to perform plasmid cloning steps, and to sequence the entirety of the swap module $\backslash$ (sequence between and including both Scel sites) before testing the cloned constructs. ${ }^{*} 2$. SWAT donor strain preparation $\backslash(\sim 5$ days) ${ }^{\star \star}$ Once prepared, the donor plasmid should now be transformed into a SWAT donor template strain using the standard Saccharomyces cerevisiae PEG/LiAC transformation protocol \(Gietz and Woods, 2002). As detailed in the table below, the template strain $\backslash(y M S 2085)$ has the following traits: his $3 \Delta 1$ leu2 $\Delta 0$ met15 $\Delta 0$ ura3 $\Delta 0$ LYS2+ can1 $\Delta::$ GAL1pr-Scel::STE2pr-SpHIS5 lyp1 $\Delta:: S T E 3 p r-L E U 2$. If you wish 
to screen for additional genetic traits across the entire library $\backslash$ (an additional fluorescent reporter, gene deletion, etc.), they may be incorporated into the genome of the donor strain at this stage. For example, one may wish to incorporate a reporter for glycosylation into each protein represented in the library, and also test this reporter on the background of a deletion in one of the genes participating in this process. Therefore this gene should be deleted in the donor strain prior to the beginning of its SGA with the SWAT library. SWAT donor template strain traits See figure in Figures section. ${ }^{*} 3$. Donor plasmid verification $\backslash$ ( 7 days) $)^{\star \star}$ Before continuing to perform high-throughput experiments, it is advisable to test swapping capability of the cloned donor plasmid on a few strains. The test strains have the same traits as the SWAT donor template strain \(see above), with the addition of a SWAT acceptor module introduced into the genome, tagging a different protein in each strain. These testing strains are provided with the library, or can be made by tagging of specific proteins with the SWAT module $\backslash$ (plasmid pST-N2). The genotype for these strains is $\backslash(\mathrm{HMG} 1$ as an example): SWAT-GFP-HMG1 ; can1 $1 \Delta:$ GAL1pr-Scel::STE2pr-SpHIS5 ; lyp $1 \Delta::$ STE3pr-LEU 2 ; his $3 \Delta 1$; leu2 $\Delta 0$ met $15 \Delta 0$; ura3 $\Delta 0$; LYS2+. Follow these steps to assure the donor plasmid functionality: 1 . Transform the donor plasmid into the test donor strains, using the selection found in the donor plasmid $\backslash$ (see 1.C). Incubate at $30^{\circ} \mathrm{C}$ for $2-3$ days, according to the transformation protocol. 2. Pick a few single colonies from each transformation, and patch them onto a fresh selection plate. Incubate at $30^{\circ} \mathrm{C}$ for 1-2 days. 3. Either pick and re-patch or replica plate $\backslash$ (using a velvet cloth) the yeast onto plates containing $2 \%$ galactose media $\backslash(\mathrm{YPGal})$. Incubate at $30^{\circ} \mathrm{c}$ for $1-2$ days. Repeat this induction step another time. - Save the plates from the previous step for comparison later on. 4. Either pick and re-patch or replica plate the yeast onto plates containing one of the following selection media: See figure in Figures section. Incubate at $30^{\circ} \mathrm{c}$ for 1-2 days. Repeat this selection step another time. 5. Repeat step 4, for another selection round. Refresh yeast from step 2. 6. Perform an experiment that enables testing the swapping of the donor module, comparing yeast before $\backslash($ step 2) and after $\backslash($ step 5) swapping. This may include a Validation by PCR, visualization of fluorescent tags, etc. $\quad * \star 4$. SGA of SWAT library with SWAT donor and tag swap $\backslash(\sim 21 \text { days })^{\star \star}$ Once the SWAT donor strain is ready it should be crossed with the SWAT library, creating haploid, double-mutant yeast. We highly recommend using the Singer RotorHD colony arrayer to preform high-throughput library plate manipulation $\backslash$ (transferring of yeast from one selection media to another, manual pinners can also be used $\backslash(V \& P$ scientific)). A complete description of the SGA method is published in numerous manuscripts $\backslash$ (Tong et al., 2001), and a full protocol was previously published by us $\backslash($ Cohen and Schuldiner, 2011). See figure in Figures section. At each step, an extra plate with the same media should be used to test growth of strains from previous steps as a control for the selection used. For example: • The diploid selection media $\backslash(\# 4)$ should be tested with the original donor strain and several colonies from the library array $\backslash$ (before mating). - At Scel induction $\backslash(\# 13)$, the original donor strain and strains from the library should be plated, and then transferred to the Swap selection $\backslash(\# 14)$ to verify that they do not grow $\backslash$ (as swapping doesn't occur in the library, and the donor plasmid should be cut in the donor). ${ }^{*} 5$. New library swap verification $\backslash$ (Timing varies by validation assay) ${ }^{\star \star}$ Validation of correct swapping events can be performed in various methods, depending on the type of swap and type of tag introduced. A. The SWAT libraries contain 3 control strains, each placed in multiple repeats per each 384 well plate. In addition, there are blank locations without any colonies. a. Check that the blank locations did not get contaminated during plate 
replication at the various stages. See figure in Figures section. B. PCR analysis can be performed, using swapped and original colonies. Primers should be planned to test both the presence of the new tag in the yeast genome, and to make sure no non-swapped yeast remain. We recommend using the following PCR reactions after swap of the N' SWAT-GFP libraries: See figure in Figures section. * Depending on the tag used. See figure in Figures section. C. Functional analysis should be performed on positive and negative control gene colonies, based on the introduced module. This may also be performed after streaking of the swapped colonies to single colonies, to assess percent of swapped vs. non-swapped clones.

\section{Timing}

$\sim 40$ days: 1. Donor module plasmid cloning $\backslash(\sim 7$ days $)$ 2. SWAT donor strain preparation $\backslash(\sim 5$ days $) 3$. Donor plasmid verification $\backslash(\sim 7$ days $) 4$. SGA of SWAT library with SWAT donor and tag swap $\backslash(\sim 21$ days) 5 . New library swap verification $\backslash$ (Timing varies by validation assay)

\section{Troubleshooting}

Failiure to achieve swapping may result from the following: 1. Selection was not achived in the SGA growth plates. To avoid this perform a control for growth from previous steps $\backslash$ (for example patch clones from the diploid selection on the haploid selection plates). 2. Donor vector design was wrong, or mutations were introduced. To avoid this we recommend sanger sequencing of the entire swapping construct between the recombination homology arms.

\section{Figures}

Feature needed

Donor module plasmid

SWAT donor strain

SWAT acceptor library
Material provided

Template plasmids

Template Strain

SWAT acceptor library

\section{Actions needed}

Cloning of desired modification and validation of swapping Introduction of the cloned donor plasmid

None

\section{Figure 1}

1 Intro Table 1 Intro Table 


\section{Swap type}

Seamless tagging

Selection reconstitution

and tag swap

Selection and tag swap $5^{\prime}$ recombination

sequence

L1

HYG $\Delta C$

L1
L2

3' recombination

sequence

L2

L2

Figure 2

Procedure Table1 Procedure Table1

\section{Swap type}

Seamless tagging

Selection reconstitution

and tag swap

Selection and tag swap

\section{Selection marker}

sequence

None

HYG $\Delta \mathrm{C}$

(TEFpr-HYG ${ }_{1-576}$ )

Full marker

sequence

\section{Selection}

introduced

None

HYG

Depending of marker selected

Figure 3

Procedure Table2 Procedure Table2 


\begin{tabular}{|c|c|c|}
\hline Class & Trait function & Genotype \\
\hline Swapping & $\begin{array}{l}\text { Inducible expression of Scel } \\
\text { enzyme }\end{array}$ & can1D::GAL1pr-Scel::STE2pr-SpHIS5 \\
\hline \multirow[t]{3}{*}{$\begin{array}{l}\text { SGA } \\
\text { procedure }\end{array}$} & $\begin{array}{l}\text { Deletions for Insertion of } \\
\text { markers }\end{array}$ & his $3 \Delta 1$ leu2 $\Delta 0$ met $15 \Delta 0$ ura $3 \Delta 0$ \\
\hline & $\begin{array}{l}\text { Haploid selection and a } \\
\text { mating type selection }\end{array}$ & can1D::GAL1pr-Scel::STE2pr-SpHIS5 \\
\hline & $\begin{array}{l}\text { Haploid selection and alpha } \\
\text { mating type selection }\end{array}$ & lyp1D::STE3pr-LEU2 \\
\hline $\begin{array}{l}\text { Functional } \\
\text { screening }\end{array}$ & $\begin{array}{l}\text { Screening reporter / } \\
\text { genetic modification }\end{array}$ & $\begin{array}{l}\text { According to the desired screen } \\
\text { objective }\end{array}$ \\
\hline
\end{tabular}

Figure 4

Procedure Table3 Procedure Table3

\section{Swap type}

Seamless tagging

\section{Selection}

5-FOA

Selection reconstitution and tag swap

Selection and tag swap

Hygromycin B

Depending of

marker selected

Figure 5

Procedure Table4 Procedure Table4 


\begin{tabular}{|c|c|c|c|c|}
\hline $\begin{array}{l}\text { Step } \\
\text { ID }\end{array}$ & Step & Media & Time & Temp. \\
\hline 1 & $\begin{array}{l}\text { Donor strain } \\
\text { liquid starter }\end{array}$ & $\begin{array}{l}\text { Liquid media with the specific donor plasmid } \\
\text { selection, e.g. YEPD+NAT (Neurseothricin, } \\
200 \mu \mathrm{g} / \mathrm{mL} \text { ). }\end{array}$ & Over night & $30^{\circ} \mathrm{C}$ \\
\hline $2 a$ & $\begin{array}{l}\text { Donor strain } \\
\text { arraying }\end{array}$ & $\begin{array}{l}\text { Agar plates with the specific donor selection (e.g. } \\
\text { YEPD+NAT). }\end{array}$ & 1 day & $30^{\circ} \mathrm{C}$ \\
\hline$\overline{2 b}$ & $\begin{array}{l}\text { SWAT library } \\
\text { arraying }\end{array}$ & Agar plates with SD-Ura. & 1 day & $30^{\circ} \mathrm{C}$ \\
\hline 3 & Mating & YEPD plates. & 1 day & RT \\
\hline 4 & Diploid selection & $\begin{array}{l}\text { Plates that contain the specific donor plasmid } \\
\text { selection, and lacks uracil (e.g. SD-Ura+NAT). }\end{array}$ & 1-2 days & $30^{\circ} \mathrm{C}$ \\
\hline $4 \mathrm{~b}$ & $\begin{array}{l}2^{\text {nd }} \text { Diploid } \\
\text { selection }\end{array}$ & $\begin{array}{l}\text { Plates that contain the specific donor plasmid } \\
\text { selection, and lacks uracil (e.g. SD-Ura+NAT). }\end{array}$ & 1-2 days & $30^{\circ} \mathrm{C}$ \\
\hline 5 & Sporulation & $\begin{array}{l}\text { Nitrogen starvation plates. Note: Do not wrap plates, } \\
\text { oxygen is essential for this step }\end{array}$ & 5-7 days & $\begin{array}{l}22^{\circ} \mathrm{C} / \\
\text { RT }\end{array}$ \\
\hline $10^{*}$ & Haploid Selection & $\begin{array}{l}\text { SD-Ura-His-Arg-Lys + canavanine + thialysine plates } \\
\text { to select for MATa haploids, or SD-Ura-Leu-Arg-Lys + } \\
\text { canavanine + thialysine plates to select for MAT } \underline{ } \\
\text { haploids. }\end{array}$ & 2 days & $30^{\circ} \mathrm{C}$ \\
\hline $12^{*}$ & $\begin{array}{l}\text { Double mutant } \\
\text { selection }\end{array}$ & $\begin{array}{l}\text { SD -His/-Leu and -Ura-Arg-Lys + canavanine + } \\
\text { thialysine + specific donor selection (e.g. NAT). }\end{array}$ & 1 day & $30^{\circ} \mathrm{C}$ \\
\hline 13 & I-Scel induction & YEPGalactose (2\%) & 1 day & $30^{\circ} \mathrm{C}$ \\
\hline 13b & $\begin{array}{l}2^{\text {nd }} \mid- \text { Scel } \\
\text { induction }\end{array}$ & YEPGalactose (2\%) & 1 day & $30^{\circ} \mathrm{C}$ \\
\hline $14^{*}$ & Swap selection & $\begin{array}{l}\text { SD -His/-Leu and -Arg-Lys + canavanine + thialysine + } \\
\text { a. Seamless tagging - 5-FOA (1g/L). } \\
\text { b. Selection reconstitution and tag swap - HYG } \\
\text { (HygromycinB, } 200 \mu \mathrm{g} / \mathrm{mL}) \text {. } \\
\text { c. Selection and tag swap - Depending of marker } \\
\text { selected (e.g NAT). }\end{array}$ & 1 day & $30^{\circ} \mathrm{C}$ \\
\hline $15^{* *}$ & $\begin{array}{l}\text { Second swap } \\
\text { selection }\end{array}$ & Same as \#14. & 1 day & $30^{\circ} \mathrm{C}$ \\
\hline
\end{tabular}

\section{Figure 6}

\section{Procedure Table5 Procedure Table5}




\begin{tabular}{|c|c|c|}
\hline Control strain & Genotype & Description \\
\hline $\begin{array}{l}\text { his } 3 \Delta 1 \text {-SWAT / } \\
\text { his } 3 \Delta 1 \text {-SWAT-SP }\end{array}$ & 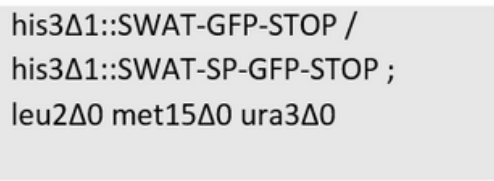 & $\begin{array}{l}\text { The SWAT-GFP / SWAT-SP-GFP module was inserted into the his3 deletion locus in } \\
\text { BY4741, with a STOP codon following the L2-linker. This strain is to be used to } \\
\text { measure either GFP levels (before swap) or the donor tag phenotype, w/o any } \\
\text { protein attached to the tag. }\end{array}$ \\
\hline his $3 \Delta 1$-GFP $\Delta C$ & $\begin{array}{l}\text { his } 3 \Delta 1:: \text { sfGPF } \Delta C \text {-Scel-URA-sfGFP } \Delta C \text {; } \\
\text { leu } 2 \Delta 0 \text { met } 15 \Delta 0 \text { ura } 3 \Delta 0\end{array}$ & $\begin{array}{l}\text { BY4741 was inserted with a fragment containing the following: L1-sfGPF } \Delta C \text {-Scel- } \\
\text { CYC1ter-URA3-NOP1pr-Scel-sfGFP } \triangle \text { C-Stop. Strain is good for auto-fluorescence } \\
\text { measurements. This strain is meant to be able to grow on -URA (with the SWAT- } \\
\text { GFP library), and also be able to lose its URA selection upon Scel induction via } \\
\text { recombination of the sfGPF } \triangle C \text { fragments. It is therefore compatible with all SGA } \\
\text { procedures, regardless of the donor plasmid used, until after the 5-FOA selection. }\end{array}$ \\
\hline $\mathrm{URA}^{+}$ & $\begin{array}{l}\Delta Y D L 121 C:: \text { URA his3 } \Delta 1 \text { leu } 2 \Delta 0 \\
\text { met15 } \Delta 0 \text { ura3 } \Delta 0\end{array}$ & $\begin{array}{l}\text { BY4741 was transformed with a URA marker inserted deleting the ORF YDL121C. } \\
\text { This control strain expresses URA3, and should be used to verify 5-FOA selection, as } \\
\text { it cannot lose it due to I-Scel induction like the library strains. }\end{array}$ \\
\hline
\end{tabular}

Figure 7

Procedure Table6 Procedure Table6

\begin{tabular}{|l|l|l|l|l|}
\hline Swap type & Validation & F primer binding site & R primer binding site & Amplicon size [bp] \\
\hline Seamless tagging & Swapped & L1 & From introduced tag & $*$ \\
\hline & Swapped & From introduced tag & L2 & $*$ \\
\hline & Original & NOP1pr & GFP tag & 494 \\
\hline Seamless GFP tagging & Swapped & L1 & GFP tag & 390 \\
\hline Selection reconstitution & Original & NOP1pr & GFP tag & 494 \\
\hline and tag swap & From introduced tag & Gene specific & $*$ \\
\hline Selection and tag swap & Swapped & From introduced tag & Gene specific & $*$ \\
\hline & Original & NOP1pr & GFP tag & 494 \\
\hline
\end{tabular}

\section{Figure 8}

\section{Primer name}

L1 CHK F

\author{
L1 CHK R
}

sfGFP CHK R

NOP1pr CHK F
Sequence $5^{\prime}-\mathbf{3}^{\prime}$

cgtacgctgcaggtcgac

catcgatgaattctctgtcg

ttcgaatttcacttctgctc

agccaacaagttttccttac 
Figure 9

Procedure Table8 Procedure Table8

Composition of the SWAT full genome library

NOP1pr-GFP

4869/5005

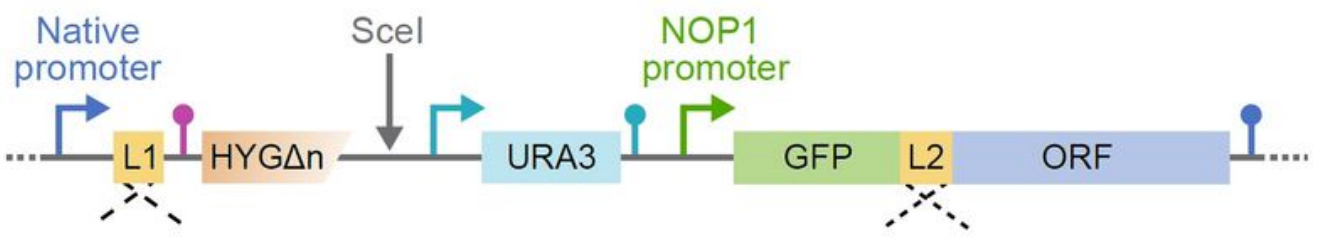

\section{NOP1pr-MTS-GFP}

369/389

Native

promoter

and MTS $\therefore$
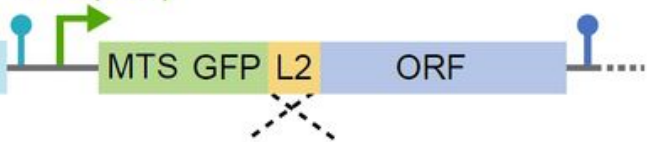

NOP1pr-SP-GFP

$318 / 336$

Native

promoter

and SP

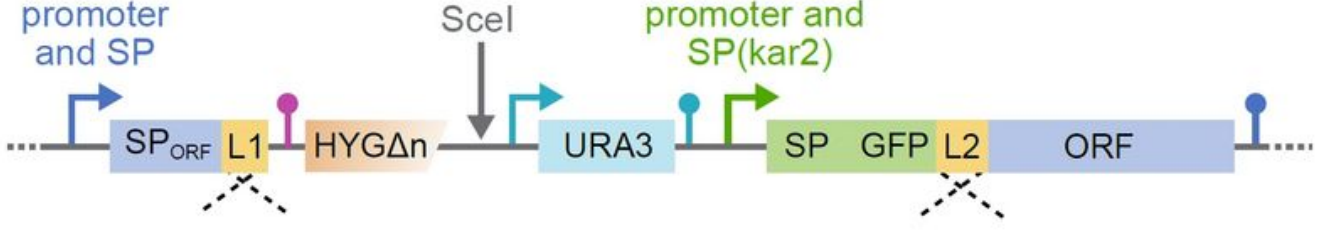

\section{Figure 10}

Figure 1 Composition of the SWAT full genome library Figure 1 Composition of the SWAT full genome library Composition of the SWAT full-genome library. Proteins were tagged at the $\mathrm{N}$ terminus with an 
acceptor SWAT module containing the NOP1 constitutive promotor (generic) and GFP. Proteins predicted to harbor a mitochondrial targeting signal (MTS) were tagged with a similar acceptor SWAT module containing an MTS upstream of GFP (MTSSu9). Proteins predicted to harbor a signal peptide (SP) were previously created (Yofe et al., 2016) with a similar acceptor SWAT module containing a SP upstream of GFP (SPKar2).

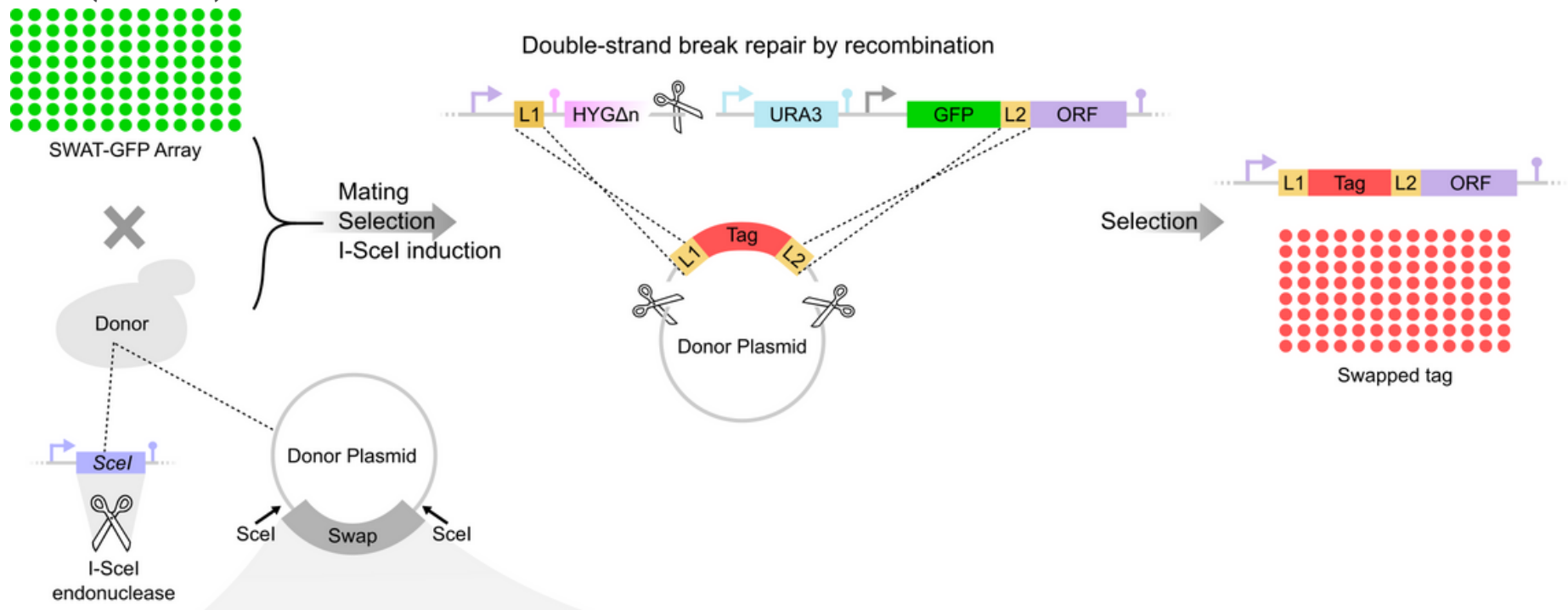

Swap donor types

1. Seamless tag swap donor

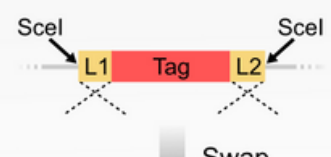

\begin{tabular}{ll|ll} 
L1 & Tag & L2 & ORF
\end{tabular}
2. Selection reconstitution and tag swap donor

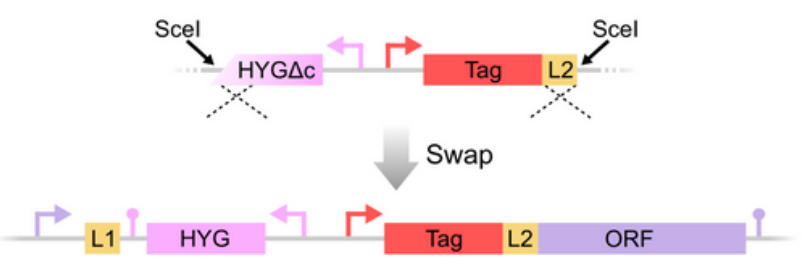

3. Selection and tag swap donor
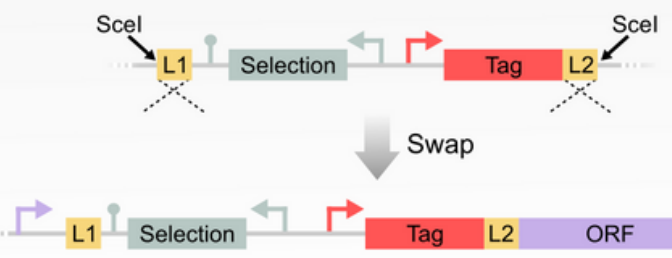

4. Seamless GFP swap donor

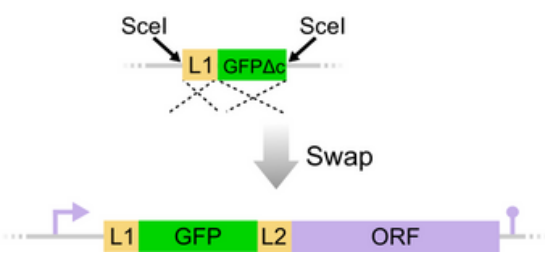

\section{Figure 11}

Figure 2 Generating new libraries with the SWAT method Figure 2 Generating new libraries with the SWAT method The SWAT-GFP library can be crossed with a donor strain to create a new library of your choice. The donor strain encodes a galactose induced I-Scel and harbors a donor plasmid with the desired tag flanked by two generic sequences (L1, L2) and two Scel restriction sites for systematic insertion (top left). An SGA procedure is used to create the new library and includes mating of the SWAT - GFP arrays with the donor strain, followed by a diploid selection step. Diploids are induced to sporulate, and thereafter 
haploids are selected for using the unique SGA markers. Next, selection is made for double mutants that contain both the acceptor tagged locus and the donor plasmid and I-Scel locus. At this point, I-Scel expression is induced by a growth step on galactose, leading to double strand breaks in the tagged gene locus and the donor plasmid. The genomic break is mended by homologous recombination of the donor tag (top middle). Correct swapping is selected for and a library featuring the new tag is created (top right). Several types of tag swaps can be carried out by using various designs of donor plasmid features, which result in several types of tagged-gene libraries (indicated by the Swap arrow). The possible swap donor types include: (1) Seamless tag swap in which proteins are fused to a new tag, restoring the native regulatory features (promoter and/or signal peptide), (2) Selection reconstitution tag swap in which a new tag is introduced with a common regulatory features (e.g. a specific promoter), and the Hygromycin selection marker is reconstituted, (3) Selection and tag swap in which both a new tag as well as a new selection marker are introduced, and (4) Seamless GFP swap in which proteins are still fused to the GFP tag, while restoring their native regulatory features (promoter and/or signal peptide). 